Pure Appl. Chem., Vol. 84, No. 3, pp. 707-719, 2012.

http://dx.doi.org/10.1351/PAC-CON-11-07-18

(C) 2011 IUPAC, Publication date (Web): 23 November 2011

\title{
Cyclization reaction of amines with dialkyl carbonates to yield 1,3-oxazinan-2-ones*
}

\author{
C. Robert McElroy ${ }^{1}$, Fabio Aricò ${ }^{1}$, Franco Benetollo ${ }^{2}$, and \\ Pietro Tundo ${ }^{1, \ddagger}$
}

\begin{abstract}
1 Università Ca' Foscari di Venezia, Dipartimento di Scienze Ambientali, Informatica e Statistica, Dorsoduro 2137, 30123, Venice, Italy; ${ }^{2}$ ICIS-CNR, Corso Stati Uniti 4, 35127 Padova, Italy
\end{abstract}

\begin{abstract}
A number of six-membered cyclic carbamates (oxazinanones) were synthesized from the reaction of a primary amine or hydrazine with a dicarbonate derivative of 1,3-diols in a one-pot reaction, in good yield, short time span, and in the absence of a solvent. The reaction proceeds in two steps: an intermolecular reaction to give a linear intermediate and an intramolecular cyclization to yield the cyclic carbamate. This is the first example of a carbonate reacting selectively and sequentially, firstly at the carbonyl center to form a linear carbamate and then as a leaving group to yield a cyclic carbamate.
\end{abstract}

Keywords: cyclic carbamates; cyclizations; dialkyl carbonate; green chemistry; heterocyclic chemistry.

\section{INTRODUCTION}

Carbamates are an important class of compounds widely used in the synthesis of pesticides [1], fungicides and herbicides [2], pharmaceuticals [3], intermediates in the fine chemical sector [4], polyurethanes [5], and as a protecting group [5]. On the other hand, cyclic carbamates are less well known. Although they have been utilized in polymerization reactions [6], it is their biological activity as antibacterials [7], anticonvulsants [8], antiepileptics [9], and enzyme inhibitors [10] that is of most interest. More specifically, oxazinan-2-ones (Fig. 1), first reported by Dox and Yoder [11], are interesting compounds with a variety of applications, most notably as a route to 1,3-amino alcohols [12,13], as chiral auxiliaries [14], and as the core substructure in a number of biologically active compounds [15].

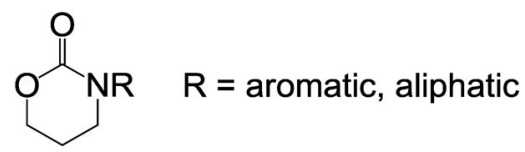

Fig. 1 1,3-Oxazinan-2-one motif.

Industrial routes to carbamates and cyclic carbamates rely upon phosgene chemistry [16], which is not desirable owing to its toxicity and environmental impact [17]. A number of routes have been found to five- and six-membered carbamates although they mostly employ isocyanates [12] or alkyl

\footnotetext{
*Pure Appl. Chem. 84, 411-860 (2012). A collection of invited papers for the IUPAC project 2008-016-1-300 "Chlorine-free Synthesis for Green Chemistry".

¥Corresponding author: Tel.: (+39) 041234 8642; Fax (+39) 041234 8620; E-mail: tundop@unive.it
} 
halides [6,7,18], or require allylic amines [19] and allylic carbamates as starting material [13]. All such syntheses involve complex starting materials and/or multistep reactions. More recently, oxazinanones have been formed utilizing $\mathrm{CO}_{2}$ as carbonylating agent, although the reactions required amino alcohols as starting material and involved stoichiometric or greater quantities of phosphosylating agents or halogen-based electrophiles [20]. A second amino alcohol and $\mathrm{CO}_{2}$-based reaction utilizing ceria nanoparticles as catalyst offers a greener route to cyclic carbamates, but requires high-pressure reactions over a long time period to give moderate yields [21]. Both reaction schemes preferentially form fivemembered rings [20,21]. Other green routes to oxazinanones employ reactions between diamines/amino alcohols and ureas [22], which occur in good yields but are limited by the availability/ease of synthesis of the starting materials. Routes to such compounds starting from amines are rare and generally require multiple steps $[11,23]$. A procedure has been developed to synthesize oxazinanones from a primary amine in one step, but it requires a stochiometric addition of dihalo alkanes [24].

In the last 20 years, dimethyl carbonate (DMC) and its derivatives have become well-known substitutes for phosgene and alkyl halides [25] and have been shown to effectively react with aliphatic $[26,27]$ and aromatic $[27,28]$ amines and hydrazines [29] to give a wide range of carbamates and methyl amines. DMC is a green reagent and solvent produced industrially by $\mathrm{CO}_{2}$ insertion into an epoxide, followed by cleavage of the resulting cyclic carbonate with methanol [30]. It has been shown to be effective for intramolecular cyclization of diols [31] through its ambiphilic electrophile properties, which can be explained through the Hard-Soft Acid-Base (HSAB) theory [32]. The reactivity of the two electrophilic centers of DMC can be selectively tuned, temperature being the key factor. In particular, at reflux temperature $\left(T=90^{\circ} \mathrm{C}\right) \mathrm{DMC}$ acts as methoxycarbonylation agent by $\mathrm{B}_{\mathrm{Ac}^{2}}$ mechanism while at higher temperature $\left(T>150{ }^{\circ} \mathrm{C}\right)$ the methylation reaction occurs via the $\mathrm{B}_{\mathrm{Al}^{2}}$ mechanism [33]. Both reactions require catalytic amount of base and produce as by-product only methanol and eventually $\mathrm{CO}_{2}$ [33].

In this work, we report the reaction between an amine and dicarbonate derivative of 1,3-, 1,4-, and 1,5-diols as a halogen-free route to cyclic carbamates through intermolecular cyclization. This is the first time that a carbonate has been reacted selectively and sequentially, firstly acting as a methoxycarbonylating agent and secondly acting as a leaving group to form a cyclic carbamate.

\section{EXPERIMENTAL SECTION}

\section{General procedure for the synthesis of dialkyl carbonates 1-2 and 11-12}

In an oven-dried 500-mL round bottom flask was added the selected diol $(0.13 \mathrm{~mol})$ in DMC (2.62 mol), followed by $\mathrm{K}_{2} \mathrm{CO}_{3}(0.26 \mathrm{~mol})$. The contents were heated to $90{ }^{\circ} \mathrm{C}$ and refluxed for $7 \mathrm{~h}$. After cooling, the product was filtered and the solvent removed under vacuum to yield the dicarbonate as a colorless oil.

Dimethyl-propane-1,3-diyl-dicarbonate 1: $(130 \mathrm{mmol}$, yield $=100 \%),{ }^{1} \mathrm{H}$ NMR $(300 \mathrm{MHz}$, $\mathrm{CDCl}_{3}$ ): $\delta=2.00-2.09$ (quintet, $2 \mathrm{H}$ ), 3.78 (br s, 6H), 4.22-4.26 (t, 4H). $\left.{ }^{13} \mathrm{C} \mathrm{NMR} \mathrm{(75} \mathrm{MHz,} \mathrm{CDCl}\right)_{3}$ : $\delta$ 28.3, 54.9, 64.5, 155.8. HRMS for $\mathrm{C}_{7} \mathrm{H}_{12} \mathrm{O}_{6}+\mathrm{Na}^{+}$calculated $\mathrm{m} / z$ 215.0532, observed $\mathrm{m} / z$ 215.0556.

Dimethyl-2-methyl-propane-1,3-diyl-dicarbonate 2: $(25.2 \mathrm{~g}, 122 \mathrm{mmol}$, yield $=93 \%),{ }^{1} \mathrm{H} \mathrm{NMR}$ (300 MHz, $\mathrm{CDCl}_{3}$ ): $\delta=1.01-1.04(\mathrm{~d}, 3 \mathrm{H}), 2.16-2.31$ (octet, $\left.1 \mathrm{H}\right), 3.78(\mathrm{~s}, 6 \mathrm{H}), 4.09-4.11(\mathrm{~d}, 4 \mathrm{H})$. ${ }^{13} \mathrm{C}$ NMR $\left(75 \mathrm{MHz}, \mathrm{CDCl}_{3}\right.$ ): $\delta 13.8,33.0,55.2,69.4,156.1$. HRMS for $\mathrm{C}_{8} \mathrm{H}_{14} \mathrm{O}_{6}+\mathrm{Na}^{+}$calculated $m / z$ 229.0688 , observed $\mathrm{m} / \mathrm{z} 229.0708$.

\section{General procedure for the synthesis of oxazinanones 3-4 and 13-16}

In an oven-dried 50-mL round bottom flask equipped with a magnetic stirrer bar and condenser was added the selected amine $(10 \mathrm{mmol})$ and the selected dicarbonate $(10 \mathrm{mmol})$, which were reacted at 
$90{ }^{\circ} \mathrm{C}$ for $2 \mathrm{~h}$ in the presence of $t \mathrm{BuOK}(1.12 \mathrm{~g}, 10 \mathrm{mmol})$. The reaction was then quenched with water $(5 \mathrm{~mL})$ and the mixture extracted with dichloromethane $(2 \times 10 \mathrm{~mL})$, dried sodium sulfate and the solvent removed under vacuum to give an oil.

3-Benzyl-1,3-oxazinan-2-one 3: Crude product was then purified via column chromatography on silica using diethyl ether to remove the by-products and then methanol to give a yellow solid which was recrystallized in diethyl ether to give a white crystalline solid (purity confirmed by NMR) $(0.762 \mathrm{~g}$, $3.97 \mathrm{mmol}$, yield $=40 \%$ ), mp 39.1-39.9 ${ }^{\circ} \mathrm{C}$ (lit. [38] 38.4-42.4), ${ }^{1} \mathrm{H}$ NMR $\left(300 \mathrm{MHz}, \mathrm{CDCl}_{3}\right)$ : $\delta=1.98-2.06$ (quint, $J=6.2 \mathrm{~Hz}, 2 \mathrm{H}$ ), $3.22-3.26(\mathrm{t}, J=6.2 \mathrm{~Hz}, 2 \mathrm{H}), 4.27-4.30(\mathrm{t}, J=5.3 \mathrm{~Hz}, 2 \mathrm{H}), 4.58$ (s, 2H), 7.28-7.36 (m, 5H). ${ }^{13} \mathrm{C} \mathrm{NMR}\left(75 \mathrm{MHz}, \mathrm{CDCl}_{3}\right): \delta 22.6,44.8,53.0,67.0,128.1,128.5,129.1$, 137.1, 154.4.

3-Benzyl-5-methyl-1,3-oxazinan-2-one 4: Crude product was then purified via column chromatography on silica using diethyl ether to remove the by-products and then methanol to give a colorless oil which was then recrystallized in 3:1 cyclohexane:diethyl ether to give a white crystalline solid (purity confirmed by NMR) $(1.078 \mathrm{~g}, 5.26 \mathrm{mmol}$, yield $=53 \%), \mathrm{mp} 49.2-49.5^{\circ} \mathrm{C},{ }^{1} \mathrm{H}$ NMR $(300 \mathrm{MHz}$, $\left.\mathrm{CDCl}_{3}\right): \delta=0.92-0.95(\mathrm{~d}, J=6.8 \mathrm{~Hz}, 3 \mathrm{H}), 2.12-2.29(\mathrm{~m}, 1 \mathrm{H}), 2.81-2.89(\mathrm{~m}, 1 \mathrm{H}), 3.13-3.21(\mathrm{~m}, 1 \mathrm{H})$, $3.83-3.90(\mathrm{~m}, 1 \mathrm{H}), 4.16-4.22(\mathrm{~m}, 1 \mathrm{H}), 4.45-4.59(\mathrm{q}, J=4.9 \mathrm{~Hz}, 2 \mathrm{H}), 7.25-7.36(\mathrm{~m}, 5 \mathrm{H}) .{ }^{13} \mathrm{C}$ NMR $\left(75 \mathrm{MHz}, \mathrm{CDCl}_{3}\right): \delta 14.3,27.4,51.6,53.0,72.2,128.1,128.5,129.1,137.1,154.2$. HRMS for $\mathrm{C}_{12} \mathrm{H}_{15} \mathrm{NO}_{2}+\mathrm{H}^{+}$calculated $\mathrm{m} / \mathrm{z}$ 206.1182, observed $\mathrm{m} / \mathrm{z} 206.1199$.

\section{By-products 5-9}

By-products 5-9 were isolated from a number of combined samples via column chromatography on silica using a gradient solvent system of 2:1 hexane:diethyl ether through to diethyl ether.

Methyl N-benzyl carbamate 5: Isolated as light yellow oil, ${ }^{1} \mathrm{H}$ NMR $\left(300 \mathrm{MHz}, \mathrm{CDCl}_{3}\right): \delta=3.60$ $(\mathrm{s}, 3 \mathrm{H}), 4.27-4.29$ (d, $J=6.0 \mathrm{~Hz}, 2 \mathrm{H}), 5.47$ (br s, 1H), 7.19-7.30 (m, 5H). ${ }^{13} \mathrm{C}$ NMR $\left(75 \mathrm{MHz}, \mathrm{CDCl}_{3}\right)$ : $\delta 45.2,52.4,127.6,127.7,128.8,139.0,157.5$. Rf 1:1 Hex:DiEtO 0.35, DiEtO 0.76.

3-Hydroxy-2-methylpropyl N-benzyl carbamate 6: Isolated as colorless oil, ${ }^{1} \mathrm{H}$ NMR $(300 \mathrm{MHz}$, $\left.\mathrm{CDCl}_{3}\right): \delta=0.90-0.93(\mathrm{~d}, J=6.9,3 \mathrm{H}), 1.85-2.00$ (octet, $\left.J=6.3,1 \mathrm{H}\right), 2.67$ (br s, $\left.1 \mathrm{H}\right), 3.40-3.54(\mathrm{~m}$, $2 \mathrm{H}), 4.0-4.17(\mathrm{~m}, 2 \mathrm{H}), 4.33-4.34(\mathrm{~d}, J=3.1,2 \mathrm{H}), 5.32($ br s, $1 \mathrm{H}), 7.23-7.35(\mathrm{~m}, 5 \mathrm{H}) .{ }^{13} \mathrm{C}$ NMR $\left(75 \mathrm{MHz}, \mathrm{CDCl}_{3}\right): \delta 13.8,36.3,45.4,64.5,67.0,127.9,129.1,138.8,157.7$ Rf 1:1 Hex:DiEtO 0.05, DiEtO 0.50. HRMS for $\mathrm{C}_{12} \mathrm{H}_{17} \mathrm{NO}_{3}+\mathrm{H}^{+}$calculated $\mathrm{m} / \mathrm{z}$ 224.1287, observed $\mathrm{m} / \mathrm{z} 224.1300$.

1,3-Dibenzylurea 7: Isolated as white crystalline solid, mp 169.1-169.7 ${ }^{\circ} \mathrm{C}$ (lit. [39] 170-171 ${ }^{\circ} \mathrm{C}$ ), ${ }^{1} \mathrm{H}$ NMR $\left(300 \mathrm{MHz}, \mathrm{CDCl}_{3}\right): \delta=4.26(\mathrm{~s}, 4 \mathrm{H}), 5.14(\mathrm{br} \mathrm{s}, 2 \mathrm{H}), 7.18-7.33(\mathrm{~m}, 10 \mathrm{H}) .{ }^{13} \mathrm{C} \mathrm{NMR}(75 \mathrm{MHz}$, $\mathrm{CDCl}_{3}$ ): $\delta 45.0,127.7,127.8,129.0,139.5,158.5$. Rf 1:1 Hex:DiEtO 0.07, DiEtO 0.56.

Methyl 2-methyl-3-(benzylcarbamoyl)propyl carbonate 8: Isolated as colorless oil, ${ }^{1} \mathrm{H}$ NMR (300 MHz, $\left.\mathrm{CDCl}_{3}\right): \delta=0.99-1.01(\mathrm{~d}, J=4.9,3 \mathrm{H}), 2.12-2.27$ (octet, $\left.J=6.6,1 \mathrm{H}\right), 3.77(\mathrm{~s}, 3 \mathrm{H})$, 3.99-4.18 (m, 4H), 5.16 (br s, $1 \mathrm{H}), 7.25-7.37(\mathrm{~m}, 5 \mathrm{H}) .{ }^{13} \mathrm{C} \mathrm{NMR}\left(75 \mathrm{MHz}, \mathrm{CDCl}_{3}\right): \delta 14.0,33.2,45.5$, 55.2, 66.5, 69.9, 127.9, 127.9, 129.1. 138.9, 156.2, 156.8. Rf 1:1 Hex:DiEtO 0.26, DiEtO 0.75. HRMS for $\mathrm{C}_{14} \mathrm{H}_{19} \mathrm{NO}_{5}+\mathrm{Na}^{+}$calculated $m / z$ 304.1161, observed $m / z 304.1154$.

2-Methylpropyl-1,3-dibenzylcarbamoyl 9: Isolated as white crystalline solid, mp 97.4-97.8 ${ }^{\circ} \mathrm{C}$, ${ }^{1} \mathrm{H}$ NMR (300 MHz, $\mathrm{CDCl}_{3}$ ): $\delta=0.95-0.98$ (d, $J=6.7,3 \mathrm{H}$ ), 2.09-2.20 (octet, $J=6.3,1 \mathrm{H}$ ), 4.03-4.06 $(\mathrm{d}, J=5.9,4 \mathrm{H}), 4.34-4.36(\mathrm{~d}, J=5.9,4 \mathrm{H}), 5.0(\mathrm{br} \mathrm{s}, 2 \mathrm{H}), 7.24-7.36(\mathrm{~m}, 10 \mathrm{H}) .{ }^{13} \mathrm{C}$ NMR $(75 \mathrm{MHz}$, $\mathrm{CDCl}_{3}$ ): $\delta 14.1,33.4,45.5,66.8,127.9,128.0,129.1,138.9,157.0$. Rf 1:1 Hex:DiEtO 0.11, DiEtO 0.63. HRMS for $\mathrm{C}_{20} \mathrm{H}_{24} \mathrm{~N}_{2} \mathrm{O}_{4}+\mathrm{H}^{+}$calculated $m / z$ 357.1814, observed $\mathrm{m} / z .357 .1831$

Dimethyl-butane-1,4-diyl dicarbonate 11: Isolated as white crystalline solid (26.4 g, $128 \mathrm{mmol}$, yield $=98 \%)$, mp 57.7-58.6 ${ }^{\circ} \mathrm{C}^{1} \mathrm{H}$ NMR $\left(300 \mathrm{MHz}, \mathrm{CDCl}_{3}\right): \delta 1.73-1.77(\mathrm{~m}, 4 \mathrm{H}), 3.76(\mathrm{~s}, 6 \mathrm{H})$, 4.13-4.17 (m 4H). ${ }^{13} \mathrm{C} \mathrm{NMR} \mathrm{(75} \mathrm{MHz,} \mathrm{CDCl}_{3}$ ): $\delta 25.5,55.1,67.7,156.1$.

Dimethyl-pentane-1,5-diyl dicarbonate 12: Isolated as colorless oil $(28.4 \mathrm{~g}, 129 \mathrm{mmol}$, yield $=$ $100 \%$ ), ${ }^{1} \mathrm{H}$ NMR (300 MHz, $\mathrm{CDCl}_{3}$ ): $\delta 1.41-1.52(\mathrm{~m}, 2 \mathrm{H}), 1.65-1.75$ (quint, $\left.J=6.9,4 \mathrm{H}\right), 3.77(\mathrm{~s}, 6 \mathrm{H})$, 
4.11-4.16 (t, $J=6.5,4 \mathrm{H}) .{ }^{13} \mathrm{C}$ NMR $\left(75 \mathrm{MHz}, \mathrm{CDCl}_{3}\right): \delta 22.5,28.7,55.1,68.2,156.2$. HRMS for $\mathrm{C}_{9} \mathrm{H}_{16} \mathrm{O}_{6}+\mathrm{Na}^{+}$calculated $\mathrm{m} / z$ 243.0845, observed $\mathrm{m} / \mathrm{z} 243.0859$.

3-Phenylamino-1,3-oxazinan-2-one 13: Crude product was precipitated out in diethyl ether $(15 \mathrm{~mL})$ and filtered to give yellow crystals, which were then recrystallized in propan-2-ol $(5 \mathrm{~mL})$, filtered and washed with diethyl ether $(2 \times 10 \mathrm{~mL})$ to give a white crystalline product (purity confirmed by NMR) $(0.583 \mathrm{~g}, 3.04 \mathrm{mmol}$, yield $=30 \%), \mathrm{mp} 143.5-143.7{ }^{\circ} \mathrm{C},{ }^{1} \mathrm{H}$ NMR $\left(300 \mathrm{MHz}, \mathrm{CDCl}_{3}\right)$ : $\delta 2.19-2.27$ (quintet, $J=6.3,2 \mathrm{H}), 3.68-3.72(\mathrm{t}, J=6.3,2 \mathrm{H}), 4.35-4.39(\mathrm{t}, J=5.3,2 \mathrm{H}), 6.33(\mathrm{~s}, 1 \mathrm{H})$, 6.76-6.79 (d, $J=8.7,2 \mathrm{H}), 6.90-6.95(\mathrm{t}, J=7.4,1 \mathrm{H}), 7.23-7.28(\mathrm{t}, J=7.3,2 \mathrm{H}) .{ }^{13} \mathrm{C}$ NMR $(75 \mathrm{MHz}$, $\left.\mathrm{CDCl}_{3}\right): \delta 23.2,49.5,67.1,113.6,121.7,129.8,146.7,154.9$. HRMS for $\mathrm{C}_{10} \mathrm{H}_{12} \mathrm{~N}_{2} \mathrm{O}_{2}+\mathrm{H}^{+}$calculated $\mathrm{m} / \mathrm{z}$ 193.0978, observed $\mathrm{m} / \mathrm{z}$ 193.1001.

5-Methyl-3-phenylamino-1,3-oxazinan-2-one 14: Crude product was precipitated out in diethyl ether $(20 \mathrm{~mL})$ and filtered to give yellow crystals, which were then recrystallized in propan-2-ol $(5 \mathrm{~mL})$, filtered, and washed with diethyl ether $(2 \times 10 \mathrm{~mL})$ to give a white crystalline product (purity confirmed by NMR) $(0.713 \mathrm{~g}, 3.46 \mathrm{mmol}$, yield $=35 \%), \mathrm{mp} 147.7-148.3{ }^{\circ} \mathrm{C},{ }^{1} \mathrm{H}$ NMR $\left(300 \mathrm{MHz}, \mathrm{CDCl}_{3}\right)$ : $\delta$ 0.99-1.02 (d, $J=6.8,3 \mathrm{H}), 2.33-2.41(\mathrm{~m}, 1 \mathrm{H}), 3.23-3.30(\mathrm{~m}, 1 \mathrm{H}), 3.51-3.57(\mathrm{~m}, 1 \mathrm{H}), 3.88-3.95$ (m, 1H), 4.18-4.23 (m, 1H), 6.72-6.75 (d, $J=7.6,2 \mathrm{H}), 6.85-6.90(\mathrm{t}, J=7.4,1 \mathrm{H}), 7.18-7.24$ (t, $J=7.5$, 2H). ${ }^{13} \mathrm{C} \mathrm{NMR}\left(75 \mathrm{MHz}, \mathrm{CDCl}_{3}\right.$ ): $\delta 14.2,28.3,55.9,72.3,113.7,121.4,129.7,146.7,154.8$. HRMS for $\mathrm{C}_{11} \mathrm{H}_{14} \mathrm{~N}_{2} \mathrm{O}_{2}+\mathrm{H}^{+}$calculated $m / z$ 207.1134, observed $m / z$ 207.1159.

3-Phenyl-1,3-oxazinan-2-one 15: Crude product was precipitated out in diethyl ether $(20 \mathrm{~mL})$ and filtered to give off-white crystals, which were then recrystallized in propan-2-ol $(5 \mathrm{~mL})$, filtered, and washed with diethyl ether $(2 \times 10 \mathrm{~mL})$ to give a white crystalline product (purity confirmed by NMR) $(0.482 \mathrm{~g}, 2.72 \mathrm{mmol}$, yield $=27 \%), \mathrm{mp} 94.5-94.7{ }^{\circ} \mathrm{C}$ (lit.[12] $\left.99{ }^{\circ} \mathrm{C}\right),{ }^{1} \mathrm{H} \mathrm{NMR}\left(300 \mathrm{MHz}, \mathrm{CDCl}_{3}\right)$ : $\delta=2.17-2.25$ (quintet, $J=6.0,2 \mathrm{H}), 3.71-3.75(\mathrm{t}, J=6.1,2 \mathrm{H}), 4.41-4.45(\mathrm{t}, J=5.5,2 \mathrm{H}), 7.24-7.43$ $(\mathrm{m}, 5 \mathrm{H}) .{ }^{13} \mathrm{C} \mathrm{NMR}\left(75 \mathrm{MHz}, \mathrm{CDCl}_{3}\right): \delta 22.9,49.2,67.4,126.3,127.2,129.6,143.4,153.2$.

5-methyl-3-phenyl-1,3-oxazinan-2-one 16: Crude product was precipitated out in diethyl ether $(20 \mathrm{~mL})$ and filtered to give off-white crystals, which were then recrystallized in propan-2-ol $(5 \mathrm{~mL})$, filtered, and washed with diethyl ether $(2 \times 10 \mathrm{~mL})$ to give a white crystalline product (purity confirmed by NMR) $(0.793 \mathrm{~g}, 4.15 \mathrm{mmol}$, yield $=42 \%), \mathrm{mp} 93.8{ }^{\circ} \mathrm{C}$ (lit. [12] $\left.92{ }^{\circ} \mathrm{C}\right),{ }^{1} \mathrm{H}$ NMR $(300 \mathrm{MHz}$, $\left.\mathrm{CDCl}_{3}\right): \delta=1.10-1.12(\mathrm{~d}, J=6.8,3 \mathrm{H}), 2.38-2.55(\mathrm{~m}, 1 \mathrm{H}), 3.38-3.45(\mathrm{~m}, 1 \mathrm{H}), 3.67-3.73(\mathrm{~m}, 1 \mathrm{H})$, 4.03-4.10 (m, 1H), 4.34-4.39 (m, 1H), 7.24-7.43 (m, 5H). ${ }^{13} \mathrm{C}$ NMR (75 MHz, $\left.\mathrm{CDCl}_{3}\right): \delta 14.2,27.7$, $55.9,72.7,126.2,127.2,129.6,143.4153 .0$.

\section{Crystal structure determination of compounds 13-16}

Crystals were lodged in glass capillaries and centered on a four-circle diffractometer using graphite monochromated MoK $\alpha$ radiation $(0.71073 \AA$ ), at room temperature, following the standard procedures. The structures were solved by standard direct methods [40] and subsequently completed by Fourier syntheses. Non-hydrogen atoms were refined anisotropically. The hydrogen atoms were introduced at the calculated positions with fixed isotropic thermal parameters ( $1.2 \mathrm{U}_{\text {equiv }}$ of the parent carbon atom). In compound 14, the disordered carbon atom $\mathrm{C}(2)$ was refining in two positions with an occupation factor of 0.5. Structure refinement and final geometrical calculations were carried out with SHELXL-97 program [41], implemented in the WinGX package [42], and drawings were produced using ORTEP-3 [43]. The data collection and structure solutions parameters are listed in the supporting information. 


\section{RESULTS AND DISCUSSION}

In the experiments here reported, primary aliphatic or aromatic amines or phenylhydrazine were reacted with dimethyl propane-1,3-diyl dicarbonate $\mathbf{1}$ and dimethyl 2-methyl-propane-1,3-diyl dicarbonate $\mathbf{2}$ in the presence of a base and in the absence of a solvent. The two steps of the reaction are clearly depicted in eqs. 1 and 2 of Scheme 1.

1)<smiles>[R19]N</smiles>

2)<smiles>[R][CH]C(=O)OCC([R2])COC(=O)O</smiles>

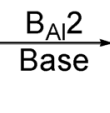

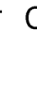<smiles>CC(=O)O</smiles>

$\mathrm{R}^{1}=\mathrm{Ph}, \mathrm{PhNH}, \mathrm{PhCH}_{2}$ $\mathrm{R}^{2}=\mathrm{H}, \mathrm{CH}_{3}$

Scheme 1 Intermolecular formation of a cyclic carbamate via intramolecular cyclization (chirality of the central carbon atom bonded to $\mathrm{R}_{2}$ is not shown).

According to the HSAB theory, in the first step (eq. 1) the amine behaves as a hard nucleophile and proceeds through a $B_{A c} 2$ pathway. The base removes a proton from the amonium-cation in the tetrahedral intermediate, promoting a methoxy anion as a leaving group and leading to the formation of the carbamate. In the second step (eq. 2), the base removes the proton from the nitrogen, producing a delocalized anion, which is softer in character and thus undergoes nucleophilic displacement of the carbonate group through $\mathrm{a} \mathrm{B}_{\mathrm{Al}^{2}}$ intramolecular cyclization pathway, leading to the cyclic carbamate.

\section{Reaction of benzylamine with dimethyl-2-methyl-propane-1,3-diyl dicarbonate 2}

Benzylamine was chosen as starting material and reacted with dicarbonates $\mathbf{1}$ and $\mathbf{2}$, giving 3-benzyl1,3-oxazinan-2-one $\mathbf{3}$ and 3-benzyl-5-methyl-1,3-oxazinan-2-one 4, respectively (Scheme 2).

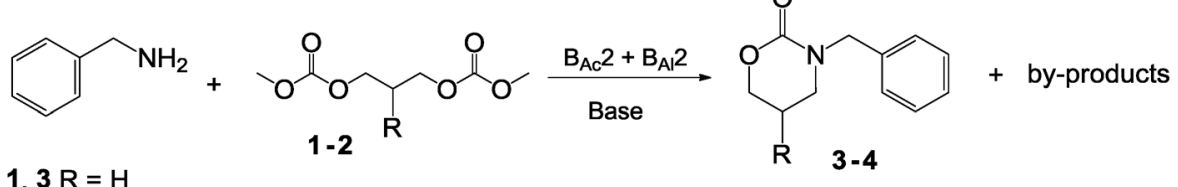

1, $3 \mathrm{R}=\mathrm{H}$

2, $4 \mathrm{R}=\mathrm{CH}_{3}$

Scheme 2 Reaction of benzylamine with dicarbonates 1 and 2.

In addition to the 1,3-oxazinan-2-ones $\mathbf{3}$ and $\mathbf{4}$, several by-products are also formed as a result of numerous concurrent reactions (Table 1). By-products derived from the reaction of benzylamine with dicarbonate $\mathbf{2}$ (Scheme 2) have been separated and identified as pure (Fig. 2). In particular, they include: methyl $N$-benzylcarbamate 5, 3-hydroxy-2-methylpropyl $N$-benzylcarbamate 6, 1,3-dibenzylurea 7, methyl 2-methyl-3-(benzylcarbamoyl)propyl carbonate $\mathbf{8}$, and 2-methylpropane-1,3-dibenzylcarbamate 9. 
Table 1 Reactions of benzylamine with dicarbonate 2 under differing conditions.

\begin{tabular}{|c|c|c|c|c|c|c|c|c|c|c|c|}
\hline \# & $\begin{array}{c}\text { Base } \\
\text { (equiv) }\end{array}$ & $\begin{array}{c}2 \\
\text { (equiv) }\end{array}$ & $\begin{array}{c}\mathrm{T} \\
{ }^{\circ} \mathrm{C}\end{array}$ & $\begin{array}{c}\text { Conv. } \\
\%\end{array}$ & & $\begin{array}{l}5 \\
\%\end{array}$ & $\begin{array}{c}6 \\
\%\end{array}$ & $\begin{array}{l}7 \\
\%\end{array}$ & $\begin{array}{c}8 \\
\%\end{array}$ & $\begin{array}{l}9 \\
\%\end{array}$ & $\begin{array}{c}\text { Others } \\
\%\end{array}$ \\
\hline 1 & None $^{\mathrm{a}}$ & 1 & 90 & 78 & 0 & 21 & 30 & 0 & 10 & 2 & 15 \\
\hline 2 & $\mathrm{~K}_{2} \mathrm{CO}_{3}(1)^{\mathrm{a}}$ & 1 & 90 & 82 & 1 & 19 & 31 & 0 & 11 & 0 & 20 \\
\hline 3 & $\mathrm{Cs}_{2} \mathrm{CO}_{3}(1)^{\mathrm{a}}$ & 1 & 90 & 89 & 3 & 22 & 40 & 1 & 4 & 5 & 15 \\
\hline 4 & $\mathrm{NaOMe}(1)^{\mathrm{b}}$ & 1 & 90 & 99 & 24 & 39 & 20 & 4 & 1 & 3 & 7 \\
\hline 5 & $\mathrm{KO}^{t} \mathrm{Bu}(1)^{\mathrm{b}}$ & 1 & 90 & 99 & $64^{c}$ & 17 & 12 & 2 & 0 & 3 & 1 \\
\hline 6 & $\mathrm{KO}^{t} \mathrm{Bu}(1)^{\mathrm{b}}$ & 1 & 30 & 99 & 52 & 19 & 19 & 0 & 2 & 5 & 2 \\
\hline 7 & $\mathrm{KO}^{t} \mathrm{Bu}(1)^{\mathrm{b}}$ & 1 & 120 & 99 & 60 & 14 & 12 & 3 & 1 & 5 & 4 \\
\hline 8 & $\mathrm{KO}^{t} \mathrm{Bu}(0.5)^{\mathrm{b}}$ & 1 & 90 & 99 & 44 & 20 & 18 & 1 & 3 & 9 & 4 \\
\hline 9 & $\mathrm{KO}^{t} \mathrm{Bu}(2)^{\mathrm{b}}$ & 1 & 90 & 92 & 58 & 14 & 12 & 2 & 1 & 1 & 4 \\
\hline 10 & $\mathrm{KO}^{t} \mathrm{Bu}(1)^{\mathrm{b}}$ & 0.5 & 90 & 96 & 36 & 17 & 20 & 10 & 4 & 6 & 3 \\
\hline 11 & $\mathrm{KO}^{t} \mathrm{Bu}(1)^{\mathrm{b}}$ & 4 & 90 & 99 & 58 & 19 & 7 & 1 & 7 & 1 & 6 \\
\hline
\end{tabular}

a 18 -h reaction time.

$\mathrm{b}_{2}$-h reaction time.

'Isolated yield (53\%).<smiles>COC(=O)NCc1ccccc1</smiles>

5<smiles>[B]C(COC(=O)NCc1ccccc1)COC(=O)OC</smiles><smiles>CC(CO)COC(=O)NCc1ccccc1</smiles><smiles>O=C(NCc1ccccc1)NCc1ccccc1</smiles>
7<smiles>CC(COC(=O)NCc1ccccc1)COC(=O)NCc1ccccc1</smiles>

Fig. 2 Major by-products of reaction of benzylamine with dicarbonate 1 (Scheme 2).

Table 1 shows the results observed for the reaction of benzylamine with the dicarbonate 2 using different bases (entries 1-5), performing the reaction at differing temperatures (entries 6 and 7) or changing the equivalents of base (entries 8 and 9) or of dicarbonate 2 (entries 10 and 11).

Initial work was carried out utilizing different bases. Results collected showed that utilizing no base or a weak base, a reaction time of $18 \mathrm{~h}$ was needed to give a good conversion of the amine ( $>75 \%)$ although a small amount of cyclic product was observed (Table 1, entries 1-3).

In these conditions numerous additional by-products were observed, each formed in low yield. Noteworthy, the intermediate $\mathbf{8}$ of the cyclic product, produced in the initial step of the reaction (Scheme 1), is formed at highest yield under these conditions. Here, intramolecular nucleophilic displacement of the methyl carbonate to give the cyclic product $\mathbf{4}$ is not favorable, thus the cyclization reaction proceeds slowly. On the other hand, when a strong base was used, the cyclic product was obtained in $64 \%$ yield and in only $2 \mathrm{~h}$ (Table 1, entry 5 ). The best results were observed employing potassium tert-butoxide. Sodium methoxide was shown to be less effective as the methoxy anion can partake in a competitive reaction with the methyl carbonate giving DMC (Scheme 3), which in turn reacts readily with the amine to give methyl $N$-benzyl carbamate 5 . 
<smiles></smiles>

Scheme 3 Formation of DMC from the reaction of dicarbonate 2 with a methoxy anion.

When potassium tert-butoxide was used, the bulky nature of its related anion inhibits such parasitic reactions [34]. In fact, entry 4 shows that $\mathbf{5}$ is formed in $40 \%$ yield in the presence of sodium methoxide (Table 1, entry 4), but only in $17 \%$ yield using potassium tert-butoxide (Table 1, entry 5). The carbamate 5 can also be formed by reaction of benzylamine reacting with the dicarbonate $\mathbf{2}$ giving the monocarbonate $\mathbf{1 0}$ as leaving group instead of methanol (Scheme 4).<smiles>COC(=O)NCc1cccc(CNCCCCO[Ge](C)(O)OCC(C)COC(=O)OC)c1</smiles>

Scheme 4 Formation of methyl $N$-benzyl carbamate 5.

The monofunctional carbonate 3-hydroxy-2-methylpropyl methyl carbonate 10 (Schemes 3 and 4) promotes the formation of many unwanted by-products. In fact, the carbamate $\mathbf{6}$ is formed through the reaction of benzylamine with $\mathbf{1 0}$ giving methanol as the leaving group (Scheme 5). This by-product can also form through transesterifcation of linear ureathanes with 2-methyl-1,3-propanediol.

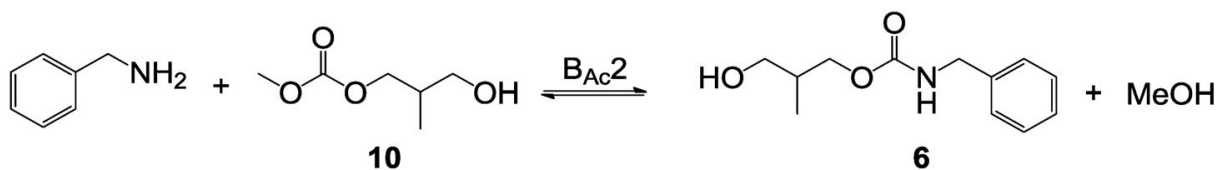

Scheme 5 Formation of 3-hydroxy-2-methylpropyl $N$-benzyl carbamate 6.

When tert-butoxide is employed, it probably behaves primarily as a base, extracting a proton from the tetrahedral intermediate, which ultimately results in the formation of the cyclic product (Scheme 6). The more hindered nature of the base limits its activity as a nucleophile and thus it might partake in the $\mathrm{B}_{\mathrm{Ac}} 2$ transesterification reactions at a lower rate (Scheme 5), so improving the yield of the cyclic carbamate.

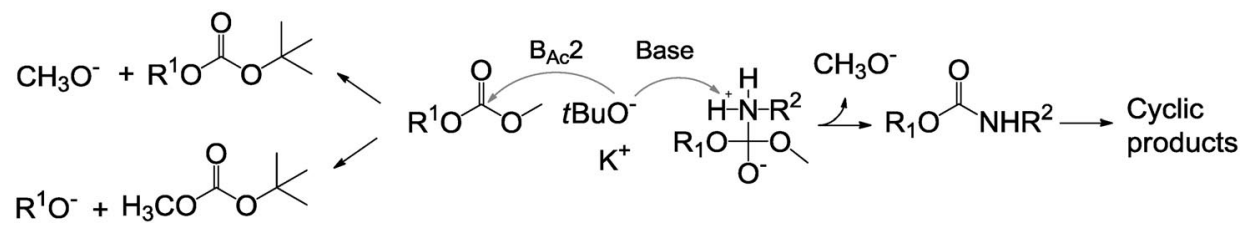

Scheme 6 Competitive reactions of tert-butoxide acting as a nucleophile or as a base. 
When the amount of tert-butoxide (entry 8 ) is diminished, the level of conversion remains high, but the yield of cyclic product 4 decreases as other by-products increase, most notably 2-methylpropyl1,3-dibenzylcarbamoyl $\mathbf{9}$. The compound $\mathbf{9}$ is thought to be formed by displacement of the methylcarboxy moiety of the intermediate $\mathbf{8}$ by benzylamine before cyclization can occur (Scheme 7).

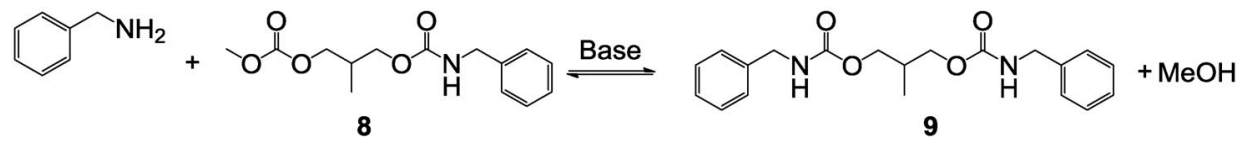

Scheme 7 Formation of 2-methylpropyl-1,3-dibenzylcarbamoyl 9.

When increasing the loading of tert-butoxide (entry 9), a lower conversion is observed, suggesting that the products of the reaction are susceptible to degradation in strong basic conditions. Utilizing an excess of benzylamine (entry 10), the yield of cyclic product $\mathbf{4}$ decreases, while the yield of by-products $\mathbf{7}$ and $\mathbf{9}$ increases. This is as both the compound $\mathbf{7}$ and $\mathbf{9}$ are formed through the reaction of benzylamine with a by-product already incorporating an aromatic group (Schemes 7 and 8).

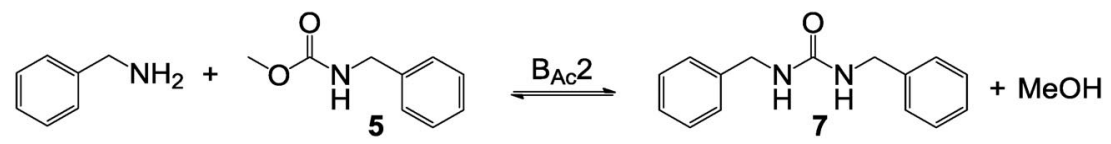

Scheme 8 Formation of 1,3-dibenzylurea 7.

An excess of dicarbonate 2 (entry 11), most likely shifts the equilibrium shown in Scheme 1 (eq. 1) increasing the yield of the cyclic intermediate 8 . Besides, the yield of the carbamate $\mathbf{6}$ decreases as the cyclic intermediate $\mathbf{8}$ increases.

All of the above listed major by-products (5-9) are formed as a result of the numerous competitive parasitic reactions that can occur together with the cyclization. However, by-product formation can be controlled by changing the reaction conditions. The results observed on the reactions of the by-products and the effect they have upon the formation of the cyclic carbamate $\mathbf{4}$ may justify the reaction mechanism reported in Scheme 1. More detailed studies are ongoing to better understand the complexity of the reaction, to further increase the yield of the cyclic product $\mathbf{4}$, and so to exploit new applications of this cyclization reaction pathway.

It is noteworthy that when the reaction was carried out in two steps (as indicated in Scheme 1), the reaction of the intermediate $\mathbf{8}$ with potassium tert-butoxide [35] gives only a $32 \%$ yield of the corresponding cyclic compound 4 [36]. The reasons for such a low yield are not yet clear at the moment; optimization of the reaction in two steps is under investigation. The mechanism here proposed is further supported by the observation that similar cyclization reactions involving benzylamine, aniline, and phenylhydrazine with dicarbonates derived from butan-1,4-diol and pentan-1,5-diol did not yield cyclic products (Scheme 9). This indicates that the $\mathrm{B}_{\mathrm{Al}^{2}}$ nucleophilic displacement shown in Scheme 1 (eq. 2) is most likely the reaction-determining step for the formation of the cyclic compound and is evidently controlled by entropic effects. 
<smiles>[Y][Y]([H])([H])COC(=O)OCCCCOC(=O)OC[CH]N</smiles>

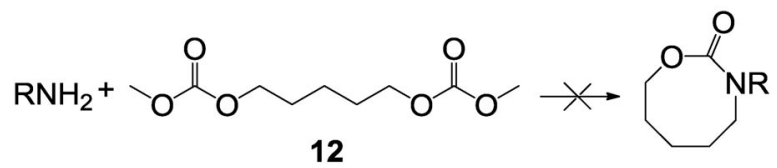

$\mathrm{R}=\mathrm{PhCH}_{2}, \mathrm{PhNH}, \mathrm{Ph}$

Scheme 9 Unsuccessful formation of seven- and eight-membered cyclic carbamates.

\section{Other cyclization reactions of benzylamine, aniline, and phenyl hydrazine with dicarbonates 1 and 2}

This investigation was extended to different starting compounds. Table 1 shows that the best conditions for synthesis of the cyclic carbamate are a 1:1:1 ratio of amine:dicarbonate:potassium tert-butoxide reacted at $90{ }^{\circ} \mathrm{C}$.

Consequently, these same conditions were used to synthesize unsubstituted cyclic carbamates by employing the dicarbonate $\mathbf{1}$ in place of $\mathbf{2}$. Additionally, phenylhydrazine was used as starting material to investigate the synthesis of cyclic carbamates. This is not obvious since in phenylhydrazine, the two nitrogen atoms are in competition and might produce a seven-membered ring system. Finally, aniline was also selected to study the reactivity of a primary aromatic amine in such cyclization reactions. Accordingly, the two carbonates $\mathbf{1}$ and $\mathbf{2}$ were reacted with benzylamine, phenyl hydrazine, and aniline (Scheme 10), and the results are reported in Table 2.

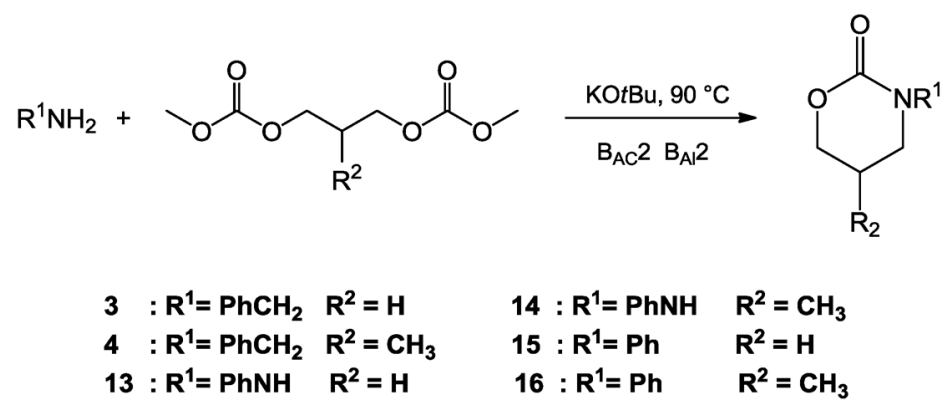

Scheme 10 General reaction pathway for one-step synthesis of 1,3-oxazinan-2-ones.

Table 2 shows that synthesis of oxazinanones from aromatic amines and hydrazines is also possible utilizing dicarbonates $\mathbf{1}$ and $\mathbf{2}$. Under such conditions, the terminal amine of hydrazine reacts selectively while the other nitrogen remains unreacted. The formation of both unsubstituted and substituted cyclic carbamates was also achieved in appreciable yield. 
Table 2 Reaction of primary amines and phenyl hydrazine with dicarbonates 1 or 2.

\begin{tabular}{|c|c|c|c|c|c|}
\hline$\#^{\mathrm{a}}$ & Amine & Dicarbonate & $\begin{array}{c}\text { Conv. } \\
\%\end{array}$ & $\begin{array}{c}\text { Cyclic } \\
\%\end{array}$ & $\begin{array}{c}\text { Others } \\
\%\end{array}$ \\
\hline 1 & $\mathrm{PhCH}_{2} \mathrm{NH}_{2}$ & 1 & 99 & $\begin{array}{c}\mathbf{3} \\
44^{\mathrm{a}}(40)^{\mathrm{b}}\end{array}$ & $54^{\mathrm{c}}$ \\
\hline $2^{d}$ & $\mathrm{PhCH}_{2} \mathrm{NH}_{2}$ & 2 & 99 & $64^{\mathrm{a}}(53)^{\mathrm{b}}$ & 35 \\
\hline 3 & $\mathrm{PhNHNH}_{2}$ & 1 & 100 & $\begin{array}{c}13 \\
65^{\mathrm{e}}(30)^{\mathrm{f}}\end{array}$ & $34^{\mathrm{c}}$ \\
\hline 4 & $\mathrm{PhNHNH}_{2}$ & 2 & 100 & $\begin{array}{c}14 \\
68^{\mathrm{e}}(35)^{\mathrm{f}}\end{array}$ & $32^{\mathrm{c}}$ \\
\hline 5 & $\mathrm{PhNH}_{2}$ & 1 & 91 & $\begin{array}{c}15 \\
52^{\mathrm{e}}(27)^{\mathrm{f}}\end{array}$ & $40^{\mathrm{c}}$ \\
\hline 6 & $\mathrm{PhNH}_{2}$ & 2 & 94 & $\begin{array}{c}16 \\
68^{\mathrm{e}}(42)^{\mathrm{f}}\end{array}$ & $23^{c}$ \\
\hline
\end{tabular}

aDetermined via HPLC analysis.

${ }^{b}$ Isolated yield through column chromatography.

${ }^{\mathrm{c} B y}$-products are consistent with those observed in Fig. 2.

${ }^{\mathrm{d}}$ Taken from Table 1.

e Determined via GCMS.

f Isolated yield through recrystallization.

The physical characteristics and NMR spectra of compounds $\mathbf{1 5}$ and $\mathbf{1 6}$ are coherent with data already reported in the literature [12]. The observed conversion of aniline into its cyclic derivative (Table 2, entries 5 and 6) is lower than that of hydrazine or benzylamine as usually the aromatic amines are weaker nucleophiles than aliphatic ones and as such do not react as readily [37]. It should be noted that although the yields obtained are comparable to those already reported in the literature, the proposed synthetic pathway is greener, simpler, and faster, and it utilizes inexpensive, readily available starting materials $[11,12]$.

\section{X-ray diffraction data}

It was possible, by the slow evaporation of a 50:50 diethyl ether:dichloromethane solution, to grow crystals of the cyclic carbamates suitable for X-ray analysis. The cyclic products of phenylhydrazine; 3-phenylamino-1,3-oxazinan-2-one 13,5-methyl-3-phenylamino-1,3-oxazinan-2-one 14, and of aniline; 3-phenyl-1,3-oxazinan-2-one 15, 5-methyl-3-phenyl-1,3-oxazinan-2-one $\mathbf{1 6}$ gave crystals suitable for analysis by single-crystal X-ray diffraction. Contrarily, the cyclic products from benzylamine gave low melting point crystals in the case of 3-benzyl-1,3-oxazinan-2-one 3, and a viscous oil in the case of 3-benzyl-5-methyl-1,3-oxazinan-2-one 4. The crystal structures of 1,3-oxazinan-2-ones $\mathbf{1 3}$ and $\mathbf{1 6}$ are reported in Figs. 3 and 4, respectively. 


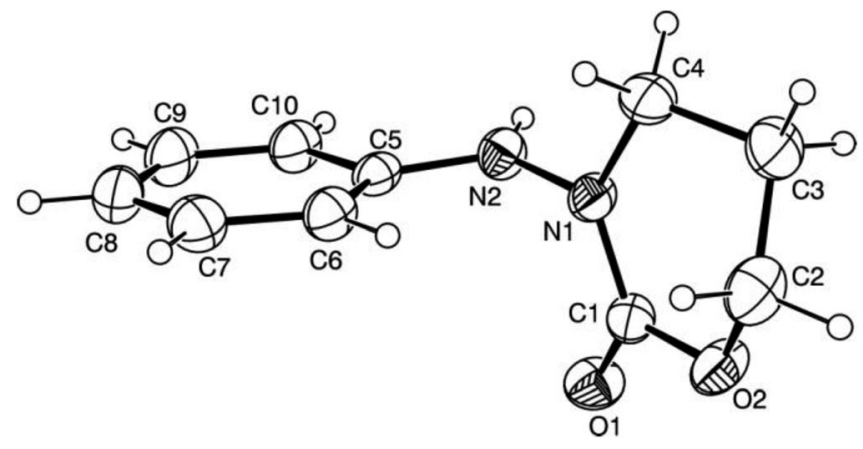

Fig. 3 X-ray crystal structure 3-phenylamino-1,3-oxazinan-2-one $\mathbf{1 3}$ (only one position of the disordered (C2) carbon atom is reported, the numbering scheme is arbitrary).

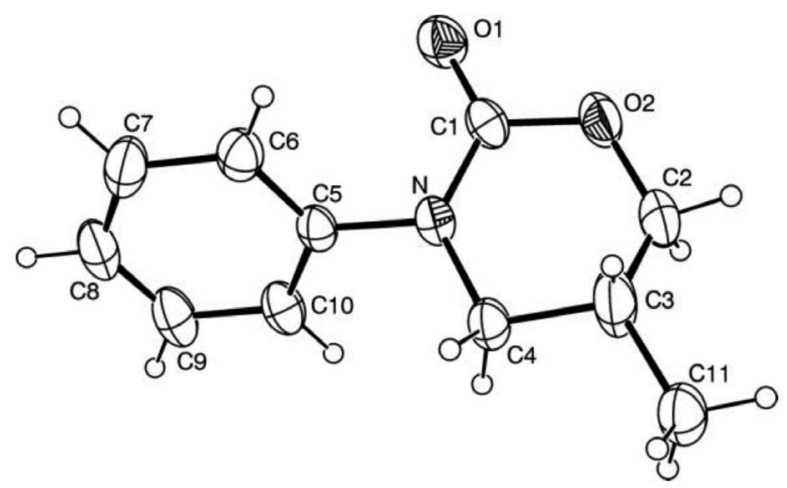

Fig. 4 X-ray crystal structure of 5-methyl-3-phenyl-1,3-oxazinan-2-one $\mathbf{1 6}$ (the numbering scheme is arbitrary).

\section{CONCLUSIONS}

Six- and seven-membered cyclic carbamates are not extensively investigated, most likely as a result of their phosgene-driven synthesis. For the first time, a method for the halogen-free synthesis of oxazinanones from primary amines and hydrazines via inter/intramolecular cyclization in reasonable yields is here reported. In some cases, confirmation of the structure of the oxazinanones has been achieved by single-crystal X-ray diffraction measurements.

This is the first time that a carbonate has been reported to react with an amine selectively and sequentially to form a cyclic carbamate. The reaction is described as an intermolecular cyclization in terms of the one-pot nature of the reaction, with two separate molecules reacting to give the cyclic carbamate. However, the reaction of the intermediate seen in the second step of the reaction (Scheme 1), forms the cyclic product via an intramolecular mechanism. In comparison with the results already reported [24], this method allows the reaction of aromatic amines and permits the functionalization of the oxazinanone ring. The low-cost and easily available starting materials, coupled with the green reaction pathway, could allow the exploitation of this methodology, leading to further and wider applications of this class of compounds and to the preparation of 1,3-amino alcohols (after hydrolysis of the cyclic carbamate). The yields, in many cases better than those already reported in the literature $[11,12]$, are, at the moment, subject to improvement as several parameters can influence the reaction outcome and deserve further optimization, i.e., the nature and the amount of the base used. This cyclization represents a step forward in halogen-free chemistry, presenting an intrinsically clean, solvent-free approach to the synthesis of oxazinanones. Computational and thermodynamic studies are also ongoing to fur- 
ther our understanding of the reaction pathway. Additionally, comparisons of this pathway to those already known [6-19] through green chemistry metrics are also in progress.

\section{SUPPLEMENTARY INFORMATION}

Supplementary Information is available online (doi:10.1351/PAC-CON-11-07-18).

\section{REFERENCES AND NOTES}

1. M. Liu, Y. Hashi, Y. Song, J. Lin. J. Chromatogr., A 1097, 183 (2005).

2. W. Tai-The, J. Huang, N. Arrington, G. M. Dill. J. Agric. Food Chem. 35, 817 (1987).

3. I. Vauthey, F. Valot, C. Gozzi, F. Fache, M. Lemaine. Tetrahedron Lett. 41, 6347 (2000).

4. P. Adams, F. A. Baron. Chem. Rev. 65, 567 (1965).

5. T. W. Greene, P. G. M. Wuts. In Protective Groups in Organic Synthesis, p. 503, Wiley-VCH, Weinheim (1998).

6. J. Kusan, H. Keul, H. Hocker. Macromolecules 34, 389 (2001).

7. G. Wang, J. Ella-Menye, V. Sharma. Bioorg. Med. Chem. Lett. 16, 2177 (2006).

8. W. J. Close. J. Am. Chem. Soc. 73, 95 (1951).

9. L. Huang, L. S. Brinen, J. Ellman. Bioorg. Med. Chem. 11, 21 (2003).

10. D. Ondre, J. Wolfling, Z. Ivanyi, G. Schneider, T. Istvan, M. Szecsi, J. Julesz. Steroids 73, 1375 (2008).

11. A. W. Dox, L. Yoder. J. Am. Chem. Soc. 45, 723 (1923).

12. (a) M. Fujiwara, A. Baba, H. Matsuda. J. Heterocycl. Chem. 26, 1659 (1989); (b) I. Shibata, K. Nakamura, A. Baba, H. Matsuda. Bull. Chem. Soc. Jpn. 62, 853 (1989); (c) A. Baba, I. Shibata, M. Fujiwara, H. Matsuda. Tetrahedron Lett. 26, 5167 (1985).

13. (a) G. T. Rice, M. C. White. J. Am. Chem. Soc. 131, 11707 (2009); (b) F. Nahra, F. Liron, G. Prestat, C. Mealli, A. Messaoudi, G. Poli. Chem.-Eur. J. 15, 11078 (2009); (c) S. Mangelinckx, Y. Nural, H. A. Dondas, B. Denolf, R. Sillanpaa, N. De Kimpe. Tetrahedron 66, 4115 (2010).

14. S. G. Davies, A. C. Garner, P. M. Robert, A. D. Smith, M. J. Sweet, J. E. Thomson. Org. Biomol. Chem. 4, 2753 (2006).

15. (a) M. Park, J. Lee. Arch. Pharmacol. Res. 16, 158 (1993); (b) X. Li, R. Wang, Y. Wang, H. Chen, Z. Li, C. Ba, J. Zhang. Tetrahedron 64, 9911 (2008).

16. Ullman Encyclopedia: Industrial Organic Chemicals: Starting Materials and Intermediates, Vol. 2, p. 1045, Wiley-VCH, New York (1999).

17. L. Cotarca, H. Eckert. Phosgenations: A Handbook, p. 589, Wiley-VCH (2004).

18. J. Jung, M. A. Avery. Tetrahedron Lett. 47, 7969 (2006).

19. Y. Kayaki, N. Mori, T. Ikariya. Tetrahedron Lett. 50, 6491 (2009).

20. J. Paz, C. Pèrez-Balado, B. Iglesias, L. Munoz. J. Org. Chem. 75, 3037 (2010).

21. R. Juárez, P. Concepción, A. Corma, H. García. Chem. Commun. 46, 4181 (2010).

22. (a) Y. J. Kim, R. S. Varma. Tetrahedron Lett. 45, 7205 (2004); (b) B. M. Bhanage, S. Fujita, Y. Ikushima, M. Arai. Green Chem. 6, 78 (2004).

23. J. X. Qiao, C. Chang, D. L. Cheney, P. E. Morin, G. E. Wang, S. R. King, T. C. Wang, A. R. Rendina, J. M. Luettgen, R. M. Knabb, R. R. Wexler, P. Y. S. Lam. Bioorg. Med. Chem. Lett. 17, 4419 (2007).

24. S. Trifunovic, D. Dimitrijevic, G. Vasic, R. D. Vukicevic, N. Radulovic, M. Vukicevic, F. W. Heinemann. Synthesis 6, 943 (2010).

25. (a) P. Tundo, M. Selva. Acc. Chem. Res. 35, 706 (2002); (b) M. Selva, P. Tundo. J. Org. Chem. 71, 1464 (2006). 
26. (a) H. Zhou, F. Shi, X. Tian, Q. Zhang, Y. Deng. J. Mol. Catal., A 271, 89 (2007); (b) M. Distaso, E. Quaranta. Appl. Catal., B 66, 72 (2006).

27. P. Tundo, S. Bressanello, A. Loris, G. Sathicq. Pure Appl. Chem. 77, 1719 (2005).

28. (a) M. Distaso, E. Quaranta. J. Catal. 228, 36 (2004); (b) T. Baba, A. Kobayashi, T. Yamauchi, H. Tanaka, S. Aso, M. Inomata, Y. Kawanami. Catal. Lett. 82, 193 (2002).

29. A. E. Rosamilia, F. Aricò, P. Tundo. J. Org. Chem. 73, 1559 (2008).

30. Y. Li, X. Zhao, Y. Wang. J. Appl. Catal., A 279, 205 (2005).

31. H. S. Bevinakatti, C. P. Newman, S. Elwood, P. Tundo, F. Aricò. Cyclic Ethers. International Patent PCT/GB2008/050567, 22 January 2009.

32. R. G. Pearson. J. Am. Chem. Soc. 85, 3533 (1963).

33. (a) M. Selva, A. Bomben, P. Tundo. J. Chem. Soc., Perkin Trans. 11041 (1997); (b) P. Tundo, M. Selva, A. Perosa, S. Memoli. J. Org. Chem. 67, 1071 (2002); (c) P. Tundo, M. Selva, A. Bomben. Org. Synth. 76, 640 (2004).

34. P. Tundo, C. R. McElroy, F. Aricò. Synlett 10, 1567 (2010).

35. After $3 \mathrm{~h}$ at $90{ }^{\circ} \mathrm{C}, 0.5$ equiv of base, in the absence of a solvent.

36. Also observed was benzylamine (4\%), methyl $N$-benzyl carbamate 5 (27\%), 3-hydroxy-2methylpropyl $N$-benzyl carbamate $6(10 \%), 1,3$-dibenzylurea $7(5 \%)$, unreacted starting material $8(14 \%)$, and 2-methylpropyl-1,3-dibenzylcarbamoyl $9(8 \%)$.

37. P. Tundo, S. Bressanello, A. Loris, G. Sathicq. Pure Appl. Chem. 77, 1719 (2005).

38. G. Y. Lesher, A. R. Surrey. J. Am. Chem. Soc. 77, 636 (1955).

39. S. Porwanski, S. Menuel, X. Marsura, A. Marsura. Tetrahedron Lett. 45, 5027 (2004).

40. M. C. Burla, R. Caliandro, M. Camalli, B. Carrozzini, G. L. Cascarano, L. De Caro, C. Giacovazzo, G. Polidori, R. Spagna. J. Appl. Crystallogr. 38, 381 (2005).

41. G. M. Sheldrick. "SHELXL-97", Program for the Refinement of Crystal Structures, University of Göttingen, Germany (1997).

42. L. J. Farrugia. J. Appl. Crystallogr. 32, 837 (1999).

43. L. J. Farrugia. ORTEP3 for Windows, J. Appl. Crystallogr. 30, 565 (1997). 